\title{
Assessment of groundwater vulnerability based on the modified DRASTIC model: A case study in Baicheng City, China
}

\author{
Mingjun Liu \\ Jilin University \\ Changlai Xiao \\ Jilin University
}

Xiujuan Liang ( $\sim 1916277955 @ q q . c o m$ )

Jilin University https://orcid.org/0000-0003-4345-7791

\section{Research Article}

Keywords: Groundwater vulnerability, DRASTIC, Three-scale analytic hierarchy process, Weights of Evidence, Nitrate

Posted Date: May 14th, 2021

DOl: https://doi.org/10.21203/rs.3.rs-460619/v1

License: (9) This work is licensed under a Creative Commons Attribution 4.0 International License. Read Full License

Version of Record: A version of this preprint was published at Environmental Earth Sciences on April 1st, 2022. See the published version at https://doi.org/10.1007/s12665-022-10350-8. 

modified DRASTIC model: A case study in Baicheng City,

\section{China}

4 Mingjun Liu ${ }^{1,2,3,4}$, Changlai Xiao ${ }^{1,2,3,4}$ and Xiujuan Liang ${ }^{1,2,3,4 *}$

$5{ }^{1}$ Key Laboratory of Groundwater Resources and Environment (Jilin University), Ministry of

6 Education, Changchun 130021, China.

$7 \quad{ }^{2}$ National-Local Joint Engineering Laboratory of In-situ Conversion, Drilling and Exploitation

8 Technology for Oil Shale, Changchun, Jilin, 130021, China

$9 \quad{ }^{3}$ College of New Energy and Environment, Jilin University, Changchun, 130021

$10{ }^{4}$ Jilin Provincial Key Laboratory of Water Resources and Environment, Jilin University

11 Abstract

12 Accurate assessment of groundwater vulnerability objectively reflects an area's

13 potential for groundwater pollution and provides a reference basis for pollution control

14 and prevention. The main objective of this study was to modify the original DRASTIC

15 model to improve the consistency of groundwater vulnerability assessment results with

16 regard to the actual conditions of the study area. To optimize the assessment objectivity,

17 two additional factors that are influenced by human activities (land use and degree of

18 groundwater extraction) were added to form the DRASTICLE model. Then, based on

19 the correlation between all factors and measured nitrate concentrations, the improved

${ }^{*}$ Corresponding authors.

E-mail address: xjliang@j]lu.edu.cn 
20 three-scale analytic hierarchy process (AHP) and the weights of evidence (WOE)

21 methods were used to reassign the factor weights of the original DRASTIC model. The

22 area under the receiver operating characteristic (ROC) curve, denoted as AUC, was

23 used to quantitatively evaluate the accuracy of all five models (original DRASTIC

24 model AUC: 0.62). By modifying the factors and weights, the four new models showed

25 better performance, AUC values were $0.75,0.76,0.85$, and 0.78 for the AHP-DRASTIC,

26 AHP-DRASTICLE, WOE-DRASTIC, and WOE-DRASTICLE models, respectively.

27 This indicates that the modified models could more accurately convey groundwater

28 vulnerability in the study area. The WOE-DRASTIC model, which had the best

29 performance, was then used to assess groundwater vulnerability in 2000 and 2010 . In

302000,2010 , and 2018, the proportion of areas with very high groundwater vulnerability

31 increased from $5.14 \%$ to $6.34 \%$ to $7.93 \%$, respectively. Meanwhile, the proportion of

32 areas with very low vulnerability also increased, from $72.63 \%$ to $75.07 \%$ to $81.60 \%$;

33 demonstrating a situation of extremes. Findings of this study are expected to provide a

34 new theoretical basis for the Baicheng municipal government in China to better manage

35 and exploit groundwater resources.

36 Keywords: Groundwater vulnerability; DRASTIC; Three-scale analytic hierarchy

37 process; Weights of Evidence; Nitrate 


\section{Introduction}

Groundwater is an important drinking water resource because of its good seasonal storage capacity, stable temperature, nonsusceptibility to pollution, and convenience for exploitation. Baicheng City is an important commodity grain base in China, and groundwater is the main water source in most parts of the area, with $90 \%$ of water resources utilization from groundwater. In recent years, with the increase in population, the development of industry and agriculture as well as urban expansion have led to an increase in the extraction of groundwater, and further, the quality of groundwater has also deteriorated. Nitrate pollution is one of the main characteristics of groundwater pollution(Almasri, 2008; Jhariya, 2019), and is mainly caused by agricultural pesticides, chemical fertilizers, and industrial wastewater pollution. Polluted groundwater conditions are not easy to identify, and once present, such pollution is difficult to control and remediate. Therefore, to improve the sustainable development and utilization of groundwater, it is necessary to develop more effective prevention and control programs for groundwater pollution. Groundwater vulnerability assessment is the premise of such resource protection, facilitating rational development as well as better land use planning and groundwater resource management.

Three main methods for groundwater vulnerability assessment include: processbased simulation (Huan et al., 2016), statistical (Bonfanti et al., 2016), and indexoverlay (Gogu \& Dassargues, 2000; Huan et al., 2012). There is a wide global application of the index-overlay method; the representative models mainly include 
DRASTIC, SINTACS, AVI, and GOD (Ferreira \& Oliveira, 2004; Ghazavi \& Ebrahimi,

61 2015). The DRASTIC model (Aller et al., 1987) is the most widely used at present,

62 owing to its ease of operation and ease of obtaining parameters. Moreover, its

63 groundwater vulnerability assessment results can be presented in the form of a

64 vulnerability map, which intuitively explains the distribution of groundwater

65 vulnerability (Al-Adamat et al., 2003; Victorine Neh et al., 2015). However, in recent

66 years, scholars have found the DRASTIC model to have certain deficiencies in the

67 selection of model factors and weights. For example, the method fixes the weight and

68 rates of each factor, without considering the actual real-world conditions, particularity

69 of the study area (Rahim Barzegar et al., 2015; Brindha \& Elango, 2015). Another

70 limitation of DRASTIC is that it does not consider the effects of human activities on

71 groundwater pollution. Therefore, it has become necessary to optimize the DRASTIC

72 model such that more objective results can be achieved in combination with the actual

73 conditions of the study area.

74 Theoretically, optimization of the DRASTIC model can be divided into two main

75 aspects. First is the optimization of the assessment factors, which can be carried out by

76 modifying the rating of factors, removing existing factors(An \& $\mathrm{Lu}, 2018$ ), or adding

77 other parameters(Khosravi et al., 2018; Omotola et al., 2020). Gogu and Dassargues

78 (2000), Babiker et al. (2005)and Wang and Yang (2008) have all suggested the addition

79 of land use into the evaluation model because this factor is strongly related to

80 groundwater vulnerability. Accordingly, Kazakis and Voudouris (2015) and Wu et al. 
81 (2018) added land use factors to modify the model, and were able to improve the model's accuracy. At the same time, for this study, different degrees of groundwater over-exploitation are known to exist in certain parts of the study area, therefore this study adds not only land use (L)(Khan \& Jhariya, 2019; Sener \& Davraz, 2012) but also the degree of groundwater extraction (E) (Abu-Bakr, 2020) into the DRASTIC model to obtain the DRASTICLE model.

The second aspect is to optimize the weight of the parameters (R. Barzegar et al., 2018; Sahoo et al., 2016) . To do this, we refer to Pacheco et al. (2015), who adopted five methods to modify the weights of the DRASTIC model, and Khosravi et al. (2018) who applied four objective methods to modify the original DRASTIC model. Other modification strategies include the analytic hierarchy process (AHP)(Bai et al., 2012; Sener \& Davraz, 2012; Thirumalaivasan et al., 2003), artificial neural network, fuzzy logic(Rezaei et al., 2013), logistic regression(Antonakos \& Lambrakis, 2007) and the weights of evidence (WOE)(Khosravi et al., 2018) which are used to optimize the weights of parameters in DRASTIC models. In this study, two objective methods were used to modify the weights: the improved three-scale AHP and the WOE. The analytic hierarchy process (Saaty \& Kearns, 1985) is simple to operate and has strong practicability and adaptability. The traditional AHP determines the judgment matrix using the nine-scale principle, yet with this method it is challenging to determine a reasonable judgment matrix because of the difficulty in grasping the importance degree among the parameters. Therefore, for this study, the three-scale method (Zuo, 1988) 
102

103

104

105

106

107

108

109

110

111 similar fields, particularly risk analyses such as landslide sensitivity analyses(Hong et

113

114 Because of the high solubility and fluidity of nitrate, this compound easily transports to

115 groundwater and is a good reflection of the degree of groundwater pollution (Shrestha

116 et al., 2016; Voutchkova et al., 2021; Wang \& Yang, 2008); thus, nitrate was selected as

117 the response factor.

118 The main objective of this study was to use the DRASTIC model to evaluate

119 groundwater vulnerability in the study area. First, the improved three-scale AHP and

120 WOE were used to optimize the parameter weights of the DRASTIC model. Second,

121 two additional parameters, land use and degree of groundwater extraction, were added

122 to obtain the DRASTICLE model. To verify the accuracy and reliability of the model, 
123 a receiver operating characteristic (ROC) curve was drawn based on the nitrate

124 concentration, and the areas under the curve (AUC) of the DRASTIC, AHP-DRASTIC,

125 AHP-DRASTICLE, WOE-DRASTIC, and WOE-DRASTICLE models were

126 compared. The most effective model was identified and then used to evaluate the

127 groundwater vulnerability of the study area in 2000 and 2010 and further analyze the

128 associated temporal and spatial distribution of groundwater vulnerability.

129

\section{Study area}

130 Baicheng City is located in the northwestern part of Jilin Province, China, west of

131 Songnen Plain, and east of the Horqin Grassland, and covers an area of approximately

$13225600 \mathrm{~km}^{2}$, between longitude $121^{\circ} 38^{\prime} 06^{\prime \prime}$ to $124^{\circ} 23^{\prime} 56^{\prime \prime} \mathrm{E}$ and latitude $44^{\circ} 13^{\prime} 57^{\prime \prime}$ to

$13346^{\circ} 18^{\prime} 15.8^{\prime \prime} \mathrm{N}$ (Fig. 1). The climate is a temperate continental monsoon with obvious

134 seasonal changes. The average annual precipitation is approximately $400 \mathrm{~mm}$, with an

135 uneven distribution throughout the year. The average annual evaporation is $1340 \mathrm{~mm}$,

136 and the annual average temperature is $4.7^{\circ} \mathrm{C}$. Low hills are situated in the northwest of

137 the study area, with elevations of 300-662.6 m. The northeastern and southeastern

138 plains are 130-140 m above sea level; in the southwest, a latent desert area is situated

$139 \quad 150-180 \mathrm{~m}$ above sea level. From the northwest to the southeast, the terrain of Baicheng

140 comprises successive low mountains, hills, and plains, and is slightly uplifted in the

141 southwest (Feng, 2019). The strata mainly include Carboniferous, Permian, Jurassic,

142 Cretaceous, Neogene, and Quaternary.

143 In 2018, the Baicheng sub-center of the Jilin Water Environment Monitoring 
144 Center performed sampling of 51 shallow groundwater monitoring wells in the city

145 plain area during both April and September, which were tested for water quality

146 parameters. The main items exceeding the standard were nitrate, ammonia nitrogen,

147 manganese, fluoride, and arsenic. It shows that groundwater has suffered from different

148 degrees of pollution. Associated land use types in the area are mainly cultivated land,

149 accounting for approximately $60 \%$ of the study area, followed by grassland and saline-

150 alkali land. From 2000 to 2018, the area of cultivated land and artificial surface both

151 increased gradually, and the proportions of grassland and forest accordingly, gradually

152 decreased.

153

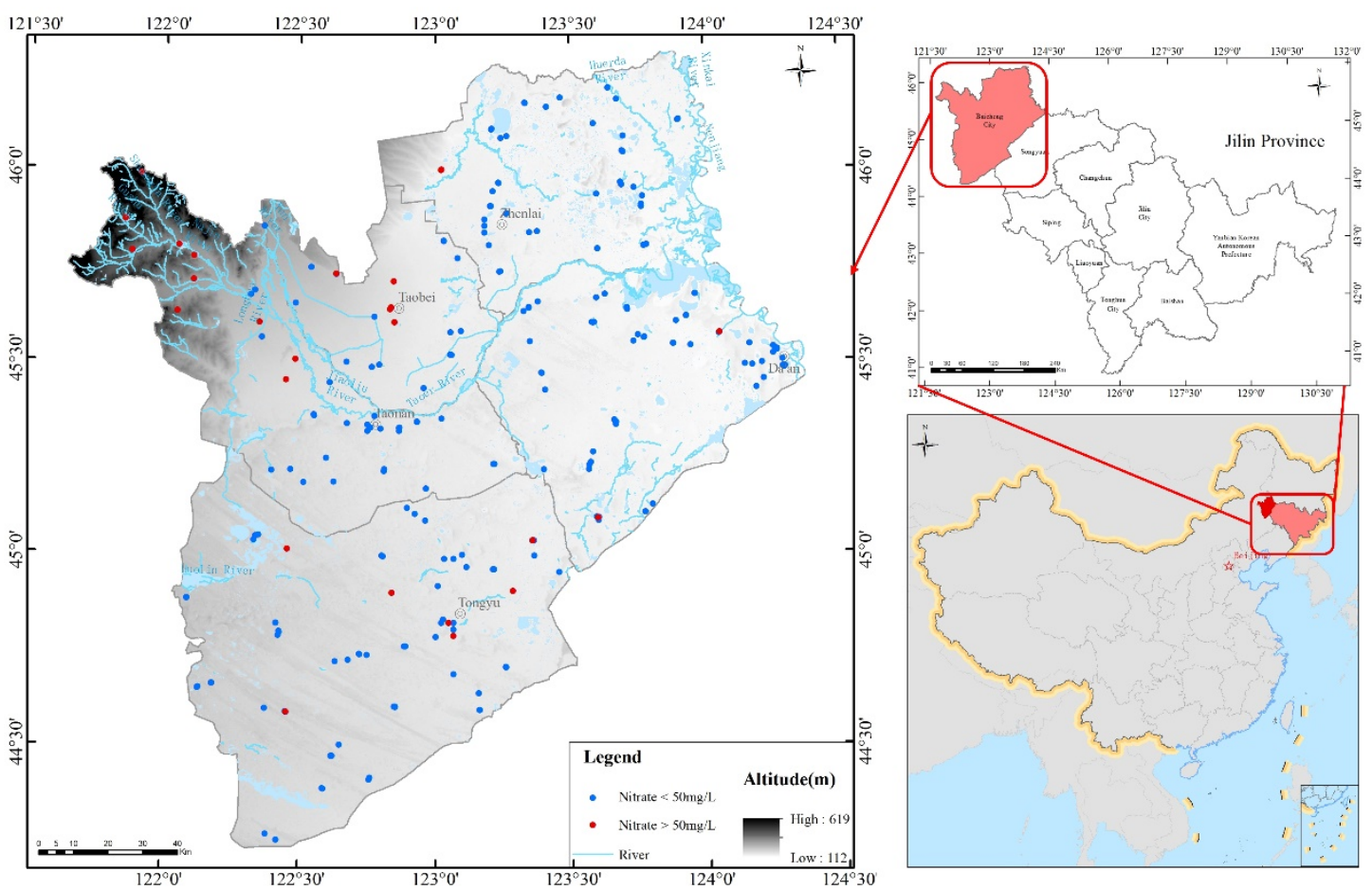

$154 \quad$ Fig. 1 Location map of the study area and showing locations of sampling wells and nitrate

distribution. 


\section{Materials and methods}

157

158

159

160

161

162 Center or measured in the field by the project team. The groundwater depth data were

163 collected from 1990 to 2018 at long-term monitoring wells, with each well dataset

164 covering January-December, measured every five days, and the number of monitoring

165 wells varied from $120-160$ to per year. Nitrate data were collected from 202 wells in

166 November 2017 by the project team and 52 wells were tested by the Baicheng Water

167 Resources Management Center in April 2018. In addition, a total of 205

168 hydrogeological boreholes were collected from this area.

169 Land use type data grids of Baicheng City in 2000, 2010, and 2018 with a

170 resolution of $30 \times 30 \mathrm{~m}$ were downloaded from the National Catalogue Service for

171 Geographic Information (http://www.webmap.cn/main.do?method=index) and

172 GLOBELAND30 (http://www.globallandcover.com/home.html?type=data).

\subsection{DRASTIC model for groundwater vulnerability}

The DRASTIC model is mainly aimed at assessing the vulnerability of an unconfined aquifer. The model selects seven factors affecting groundwater flow and

176 pollutant transport as vulnerability assessment parameters: depth to groundwater (D),

177 net recharge $(\mathrm{R})$, aquifer media $(\mathrm{M})$, soil media $(\mathrm{S})$, topography $(\mathrm{T})$, impact of the 
178

179

183 index (VI) was calculated using Eq. 1:

$$
\mathrm{VI}=D_{r} D_{w}+R_{r} R_{w}+A_{r} A_{w}+S_{r} S_{w}+T_{r} T_{w}+I_{r} I_{w}+C_{r} C_{w}
$$

vadose zone (I), and conductivity of the aquifer (C). For this study, each parameter was classified according to its range of variation and internal attributes, and the corresponding vulnerability ratings were given; the larger the rating, the higher the vulnerability grade. The rating and weight of each factor for groundwater vulnerability have been previously described by Aller et al. (1987). The groundwater vulnerability where the subscripts $\mathrm{r}$ and $\mathrm{w}$ represent the ratings and weights for the seven parameters of the DRASTIC model, respectively.

Bojórquez-Tapia et al. (2009) indicated that five categories of groundwater vulnerability should be appropriate for conveying meaningful information to planners, decision-makers, and stakeholders. Therefore, in this study, the groundwater vulnerability index was divided into five categories: very low, low, moderate, high, and very high.

\subsection{Preparation of DRASTIC parameters}

Based on the original DRASTIC model, two factors affected by human activities, namely the type of land use (L) and degree of groundwater extraction (E), were added to generate the DRASTICLE model. All factors used in the model are described for this study as follows.

Depth to groundwater (D). The depth to groundwater determines the contact time between the surface pollutants and aeration zone media before entering the aquifer. 
198 Generally speaking, the greater the depth to groundwater, the greater the probability of

199 pollutant attenuation and oxidation, and the lower the vulnerability of groundwater. The

200 inverse distance weight tool of ArcGIS was used to process the groundwater table depth

201 data of 120 long-observation wells in the research area, and the depth of the

202 groundwater distribution map in the area was obtained. The groundwater depth was

203 divided into five depth groups: $1.2-1.5,1.5-4.6,4.6-9.1,9.1-15.2$, and $15.2-17.3 \mathrm{~m}$,

204 and the corresponding ratings were given. The results are presented in Fig. 2a.

205

Net recharge (R). Contaminants on the surface or soil can be transported vertically

206 to groundwater through recharge water and transported within the aquifer. The greater

207 the precipitation recharge, the greater the possibility of pollutants reaching the aquifer,

208 that is, the greater the vulnerability trend of groundwater pollution. Many recharge

209 sources of groundwater exist in the study area, including precipitation infiltration,

210 lateral recharge in mountainous areas, river channel leakage, and well irrigation return

211 recharge. The net recharge ranged from 51.2 to $236.8 \mathrm{~mm}$ and was divided into three

212 categories, the results of which are shown in Fig. $2 b$.

213 Aquifer media (A). The pore characteristics of the aquifer media determine the

214 velocity of groundwater flow and affect the adsorption, diffusion, and dispersion of

215 pollutants. In general, larger aquifer medium particles and more pores leads to the

216 presence of better permeability, and lower probability of the pollutants being diluted

217 and attenuated; thus, the higher the groundwater vulnerability. The object of this study

218 was an unconfined aquifer, for which the fissure water aquifer was dominated by granite, 
219 and the pore water aquifer was dominated by gravelly pebbles, loess sub-sand, and silty-

220 fine sand. The Taoer River Fan phreatic aquifer is mainly composed of gravel and 221 pebble gravel; sandy alluvial lacustrine plain is dominated by medium fine sand, fine 222 sand, and silt, and the lithology of the swamp and saline-alkali valley is dominated by 223 loess sandy soil (Fig. 2c).

224 Soil media (S). The soil medium affects the amount of surface water infiltrating 225 underground, as well as the ability of pollutants to enter the aeration zone vertically. 226 The surface of the study area is overlain by Upper Pleistocene and Holocene systems. 227 The underlying Lower Pleistocene material is mainly distributed in the platform, which 228 is a glacial moraine with a high clay content. The moraine deposits of the Upper 229 Pleistocene Zhenxi Ice Age are mainly distributed in the fan and in the Taoer River and 230 Jiao Liu River valleys. The upper ice-water accumulation layer is mainly composed of 231 gravel, sand, and gravel with minimal clay, and is interbedded with clay, sub-clay, and 232 fine sand lenses. The alluvium of the Guxiangtun Formation, which is mainly 233 distributed in the alluvium plain, is a loess-like subsandy soil. Holocene alluvial 234 deposits, which are distributed in the floodplain of the Taoer, Jiaoliu, and Hanhe rivers, 235 as well as along the periphery of the fan front, are mainly composed of gravel, sand, 236 gravel, and feature a subsandy soil layer. The associated aeolian sediments are 237 comprised of yellow and white fine sand (Fig. 2d). Topography (T). Slope mainly affects the infiltration of atmospheric precipitation.

239 The lower the slope, the more infiltration is generated; thus, the higher the potential for 
240 pollution. Slope distribution was extracted from digital elevation model data of

241 Baicheng City using the ArcGIS surface analysis tool. The terrain in the study area is

242 relatively gentle overall, though the hilly area in the northwest is relatively steep, with

243 a topographic slope of up to $70 \%$. The slopes in the area were categorized as $0-2 \%, 2-$

$2446 \%, 6-12 \%, 12-18 \%$, and $>18 \%$ (Fig. 2 e).

245 Impact of the vadose Zone (I). The vadose zone controls the length of the

246 infiltration path and seepage path of the surface water. The soil layer of the vadose zone

247 has a remarkable ability to adsorb and block the entry of pollutants into groundwater.

248 The better the sorting, the finer the particles and the higher the clay content of the

249 vadose zone medium; thus, the worse the permeability, the stronger the adsorption and

250 purification ability, the stronger the pollution prevention performance, and the weaker

251 the groundwater vulnerability, hence the greater the vulnerability of the groundwater.

252 The main lithologies in the vadose zone of the study area were found to be clay gravel,

253 sub-sand, silty sand, loess sub-sand, sub-sand, gravel, gravel-bearing loess sub-sand,

254 silt sub-clay, sand gravel, loess sub-clay, and gravel-bearing sub-sand. In the Taoer

255 River Fan area, the lithology of the vadose zone was mainly gravel, while the valley

256 area was sub-clay, and in the western low plain, the vadose zone was mainly silty sand

257 and loess sub-sandy soil (Fig. 2f).

258 Conductivity of the aquifer (C). It controls the flow rate of groundwater and the

259 migration rate of pollutants into aquifers. The conductivity of the aquifer varied

260 significantly. Using the obtained permeability coefficient values of 157 wells, the 
261 distribution of hydraulic conductivity in the area was obtained by simple kriging

262 difference values, and the distribution pattern was roughly the same as the lithological

263 distribution, ranging from $0.65-470.36 \mathrm{~m} / \mathrm{d}$. The Taoer River Fan had the largest

264 hydraulic conductivity (Fig. 2g).

265 Land use (L). The types and degree of pollution of pollutants produced by different

266 land use types in the study area varied widely, while the surface cover can also be

267 expected to have a great impact on the interception capacity of pollutants and the

268 manner in which pollutants enter the aquifer. Typically, the vulnerability of

269 groundwater in industrial areas is high, mainly because the distribution of factories is

270 concentrated, and if the production wastewater is not discharged according to

271 regulatory standards or is treated improperly and leakage occurs, the wastewater will

272 likely become a potential source of groundwater pollution. In agricultural areas, wide-

273 spread application of a variety of pesticides, fertilizers, and livestock and poultry

274 manure can easily produce surface pollution sources, which pose a threat to

275 groundwater quality. In green belt areas, such as grassland and forest, surface plants

276 have the function of reducing surface runoff, reducing soil erosion, and adsorbing

277 pollutants, thus such plants have a certain protective effect on groundwater, and the

278 vulnerability of groundwater in these areas is lowest. The land use types in the study

279 area were mainly divided into artificial surface, forest, water bodies, wetland, shrubland,

280 cultivated land, grassland, and bare land (Fig. 2h).

281 Degree of groundwater extraction (E). Groundwater exploitation intensity is 
282 another major factor affecting groundwater vulnerability. Excessive exploitation of 283 groundwater leads to an increased drop in groundwater levels and a larger scope of 284 groundwater draw-down funnels, resulting in an increased hydraulic gradient. 285 Meanwhile, as the formation of surface water and surrounding runoff stimulates 286 groundwater recharge; groundwater becomes more vulnerable to pollution, which 287 increases the vulnerability of the groundwater environment. The degree of groundwater 288 extraction is the ratio of the actual extraction amount to the recoverable amount. The 289 degree of groundwater extraction in Taobei District was 94\%, the proportion of Taonan 290 City in the Huolin River Basin was $14 \%$, and most of the other areas were between $20 \%$ 291 and 50\% (Fig. 2i). 




293 Fig. 2 Maps of groundwater vulnerability conditioning factors: (a) depth to groundwater, (b) net

294 recharge, (c) aquifer media, (d) soil media, (e) topography, (f) impact of the vadose zone,(g)

295 conductivity of the aquifer, (h) land use, and (i) degree of groundwater extraction.

\subsection{Factors correlation test}

298 The evaluation factors in the model were expected to be relatively independent 
299 and have no strong correlation; therefore, multi-collinearity diagnosis was performed 300 among the evaluation factors (Arabameri et al., 2019; O'Brien, 2007) to derive the 301 tolerance and variance inflation factor (VIF), with the thresholds of tolerance $<0.1$ and 302 VIF $>10$ indicating strong multi-collinearity. The random point creation tool of ArcGIS 303 which was adopted to create 10000 random points in the research area, extract the rating 304 values of nine parameters corresponding to each point, and calculate the tolerance and 305 VIF using SPSS software.

\subsection{Optimization of DRASTIC model weights}

\section{$307 \quad$ 3.5.1 Three-scale analytic hierarchy process}

The three-scale AHP was used to modify the weights of the original DRASTIC and DRASTICLE models, and has the same calculation steps as the traditional AHP.

310 The three-scale method was used to replace the original nine-scale method in order to

311 better construct the judgment matrix. The AHP was required to compare and judge 312 parameters and determine the order of their importance, the significance scale 313 comparison is presented in Table 1. In order to determine the magnitude relationship, a 314 correlation analysis between each parameter and the actual nitrate concentration was 315 carried out; the higher the correlation with nitrate, the more important the parameter. In 316 this way, the degree of importance of each parameter in the vulnerability assessment 317 could be determined. 
321 according to Eqs. 1 and 2 , respectively.

324 of the DRASTICLE model, respectively.

\subsubsection{Weights of evidence} under the assumption of independent conditions.

330 of area $\mathrm{U} \mathrm{km}^{2}$, the total number of cells in the study area is $\mathrm{N}(\mathrm{T})=\mathrm{A}(\mathrm{T}) / \mathrm{U}$. Assuming

331 that there are N(D) cells with response factor (D) distribution, the probability of the 332 occurrence of a response factor in any cell selected in the research area is $P(D)=N(D) /$

$333 \mathrm{~N}(\mathrm{~T})$, which is called the prior probability. It is assumed that the prior probabilities of

334 each cell are equal throughout the study area. Then, the prior probability is expressed 335 in terms of the odds $(\mathrm{O})$ :

$$
\mathrm{O}(\mathrm{D})=\frac{P(D)}{1-P(D)}=\frac{N(D)}{N(T)-N(D)} .
$$




$$
\begin{aligned}
& W^{+}=\ln \frac{P\{B \mid D\}}{P\{B \mid \bar{D}\}}=\ln \frac{N(B \cap D) / N(D)}{N(B \cap \bar{D}) / N(\bar{D})} ; \\
& W^{-}=\ln \frac{P\{\bar{B} \mid D\}}{P\{\bar{B} \mid \bar{D}\}}=\ln \frac{N(\bar{B} \cap D) / N(D)}{N(\bar{B} \cap \bar{D}) / N(\bar{D})}
\end{aligned}
$$

where $\mathrm{B}$ is the model factor, and $\mathrm{D}$ is the response factor (nitrate concentration).

338 The weight contrast is $C=W^{+}-W^{-}$, and the standard deviation of the weight 339 difference is $\sigma=\sqrt{\sigma^{2}\left(W^{+}\right)+\sigma^{2}\left(W^{-}\right)}$, where $\sigma^{2}\left(W^{+}\right)$and $\sigma^{2}\left(W^{-}\right)$are the

340 variances of $\mathrm{W}^{+}$and $\mathrm{W}^{-}$, respectively. The final weight is $W=\frac{C}{\sigma(C)}$.

$$
\begin{aligned}
& \ln \mathrm{R}=\ln \left\{O\left[\frac{D}{B_{1}^{k} B_{2}^{k} \cdots B_{n}^{k}}\right]\right\}=\sum_{j=1}^{n} W_{j}^{k}+\ln O(D) ; \\
& (\mathrm{j}=1,2,3 \cdots, \mathrm{n}) .
\end{aligned}
$$

344 Finally, by using the formula $\mathrm{P}=\frac{R}{1+R}$, the logarithm of the posterior odds can be 345 transformed into posterior probability.

\subsection{Comparison and validation of models}

To validate and compare the accuracy of the five models, the ROC curve

348 (Mukherjee \& Singh, 2020) was used to evaluate and compare the results of different

349 models, which takes each value of the predicted results as the possible judgment

350 threshold, and calculates the corresponding sensitivity and specificity accordingly. The

351 false positive rate ( 1 - specificity) is taken as the horizontal coordinate, and the true 352 positive rate, that is, sensitivity, is drawn as the vertical coordinate. The area under the 
ROC curve, the AUC value, is a good measure of the model's predictive accuracy, and

354 ranging in value from 0.5 to 1 ; the larger the value, the stronger the judgment of the 355 model. In this study, an ROC curve was drawn based on the groundwater nitrate 356 concentration and groundwater vulnerability index.

\section{Results and discussion}

\subsection{Multi-collinearity diagnosis}

The results of the multi-collinearity diagnosis for each evaluation factor are presented in Table 2. The tolerance and VIF were $0.35-0.97$ and 1.04-2.84, respectively,

361 both meeting the conditions of tolerance $>0.1$ and $\mathrm{VIF}<10$, which indicates that there 362 was no overlap among the nine evaluation factors; thus, the conditions were 363 independent and could participate in the model evaluation.

Table 2 Multi-collinearity diagnosis test for all conditioning factors

\begin{tabular}{lcc}
\hline Factors & Tolerance & VIF \\
\hline Depth to Water & 0.89 & 1.12 \\
Net Recharge & 0.46 & 2.18 \\
Aquifer Media & 0.53 & 1.87 \\
Soil Media & 0.52 & 1.93 \\
Topography & 0.85 & 1.18 \\
Impact of the Vadose Zone & 0.66 & 1.52 \\
Conductivity of the Aquifer & 0.62 & 1.62 \\
Land use & 0.97 & 1.04 \\
Degree of Groundwater Extraction & 0.35 & 2.84 \\
\hline
\end{tabular}

4.2 Groundwater vulnerability assessment using original DRASTIC 367 model

According to the original DRASTIC model, the minimum and maximum values 
371 Jenks method in ArcGIS, and a groundwater vulnerability distribution map was drawn 372 (Fig. 3a).

373 The very low (I) vulnerability region accounted for $9.32 \%$ of the study area, 374 mainly distributed in the hilly area in the northwest. The areas with low (II) 375 vulnerability were the most distributed, accounting for $41.25 \%$ of the study area; the 376 moderate (III), high (IV), and very high (V) vulnerability regions accounted for $28.97 \%$, $37715.12 \%$, and $5.35 \%$ of the study area, respectively. Based on this, the overall 378 groundwater vulnerability in the study area was considered relatively low.

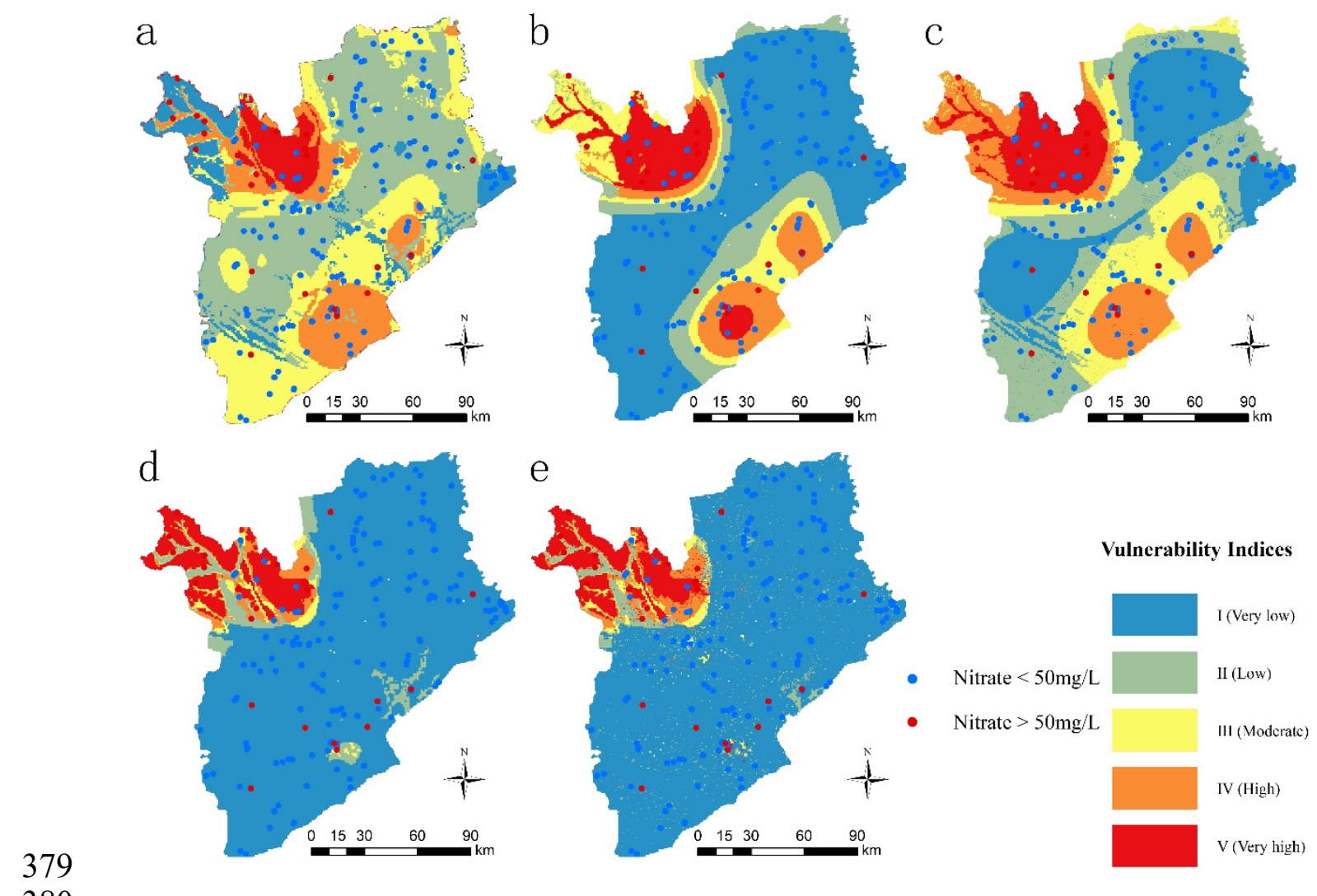

Fig. 3 Groundwater vulnerability maps: (a)DRASTIC, (b)AHP-DRASTIC, (c) AHP- 


\subsection{Groundwater vulnerability assessment using three-scale AHP}

To verify the consistency of the judgment matrix, the consistency index values of

385 the AHP-DRASTIC and AHP-DRASTICLE models were 0.025 and 0.047 ,

386 respectively, both of which were $<1$, indicating that the normalized weight values

387 passed the consistency test. The weights of the evaluation factors for the two models 388 are listed in Table 3.

Table 3 Modified weights of the AHP-DRASTIC and AHP-DRASTICLE factors

\begin{tabular}{lcc}
\hline \multirow{2}{*}{ Factors } & \multicolumn{2}{c}{ Weight } \\
& AHP-DRASTIC & AHP-DRASTICLE \\
\hline D (Depth to Groundwater) & 0.019 & 0.010 \\
R (Net Recharge) & 0.030 & 0.023 \\
A (Aquifer Media) & 0.152 & 0.097 \\
S (Soil Media) & 0.257 & 0.244 \\
T (Topography) & 0.087 & 0.060 \\
I (Impact of the Vadose Zone) & 0.050 & 0.037 \\
C (Conductivity of the Aquifer) & 0.405 & 0.359 \\
L(Land use) & & 0.015 \\
E(Degree of Groundwater Extraction) & & 0.156 \\
\hline
\end{tabular}

391 According to the weights in Table 3, the evaluation factors of the two models were

392 weighted and superimposed to obtain the distribution map of groundwater vulnerability

393 in the study area, as shown in Figs. 3b, c. According to the two models, the groundwater

394 vulnerability in the study area was very low (I) and low (II).

395 4.4 Groundwater vulnerability assessment using WOE

396 Taking the nitrate concentration as the response factor, there were 254 nitrate

397 points in the study area. Monitoring wells with $\mathrm{NO}_{3}{ }^{-} \geq 50 \mathrm{mg} / \mathrm{L}$ were selected as the

398 response factor occurrence point, and there were 26 points with $\mathrm{NO}_{3}{ }^{-} \geq 50 \mathrm{mg} / \mathrm{L}$. The 
399 probability of the occurrence of the response factor was $\mathrm{P}(\mathrm{D})=0.102$, and the prior

400 probability odds were $\mathrm{O}(\mathrm{D})=\frac{P(D)}{1-P(D)}=0.114$. The weights calculated according to Eqs. 4 401 and 5 are shown in Supplementary Table S. 403 According to the weights in Attached Table A, among the factors affecting 404 groundwater vulnerability, depth to groundwater (D) at 4.6-9.1 m had the highest 405 impact (1.668) on groundwater vulnerability, net recharge (R) at 177.8-254 mm, 406 aquifer media (A) at sand and gravel, soil media (S) at loam, topography (T) at 2-6\%, 407 impact of the vadose zone (I) at sand and gravel, conductivity of the aquifer (C) at $>81.5$ $408 \mathrm{~m} / \mathrm{d}$, land use (L) at artificial surface, and degree of groundwater extraction (E) at 50$40970 \%$ had the most effect on groundwater pollution probability, respectively.

410 According to Eq. (6), the posterior probabilities of the response factors of the 411 WOE-DRASTIC and WOE-DRASTICLE models were calculated. The results were 412 classified into five categories using the Jenks method, as shown in Figs. 3d, e. The 413 assessment of groundwater vulnerability by WOE showed that the vulnerability of the 414 WOE-DRASTIC and WOE-DRASTICLE models were mainly very low (I), 415 accounting for $81.60 \%$ and $81.52 \%$ of the total area, respectively.

\section{$416 \quad 4.5$ Evaluation and comparison of model results}

417 As can be seen from Fig. 4, the AUC of the original DRASTIC model is the 418 minimum (0.62), improved by the three-scale AHP, and the AUCs of AHP-DRASTIC 419 and AHP-DRASTICLE were 0.75, and 0.76, respectively. The AUC of WOE- 
421 indicates that the results of the two methods (AHP and WOE) were better than those of

422 the traditional DRASTIC assessment. The three-scale AHP method with the addition of

423 two evaluation factors yielded better model results, while the result of WOE-DRASTIC

424 (seven factors) was better than WOE-DRASTICLE with nine factors. This is because

425 the weights calculated for a small number of classes are more robust than those

426 calculated using a large number of classes, and this is particularly critical when a

427 relatively small number of points are in the training data(Antonakos \& Lambrakis, 428 2007).

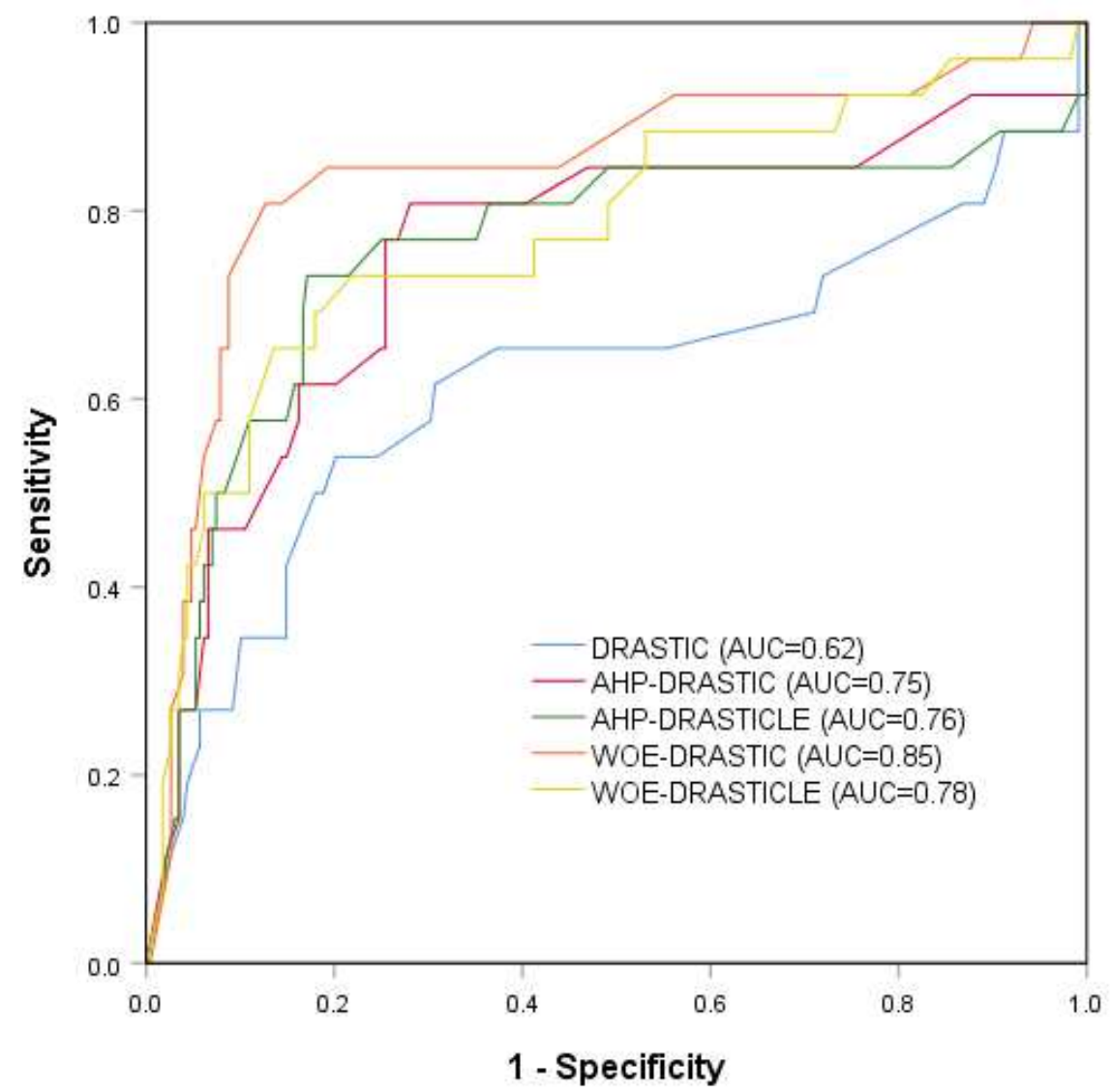

429

Fig. 4 ROC curve 

depth of groundwater data.
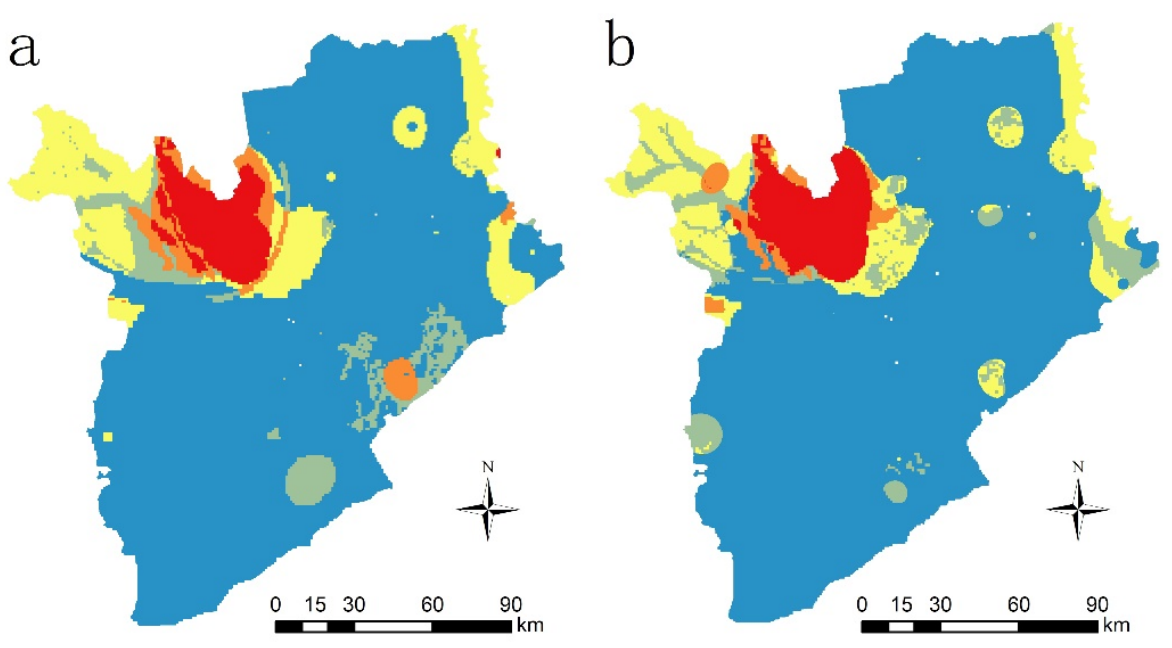

Vulnerability Indices

\subsection{Changes in groundwater vulnerability over time}

To study the temporal and spatial pattern change of groundwater vulnerability, explore its distribution characteristics in different periods, and predict its development trend, the most effective model, the WOE-DRASTIC model, was selected to evaluate the groundwater vulnerability in 2000 and 2010. The distribution of groundwater vulnerability is shown in Fig. 5. In 2000, the very low (I) vulnerability zone accounted for $72.63 \%$, and the very high (V) vulnerability zone accounted for only $5.14 \%$, mainly distributed in the Taoer River Fan. In 2010, the areas of very low (I) and very high (V) groundwater vulnerability accounted for $75.07 \%$ and $6.34 \%$, respectively. The very low (I) vulnerability zone for $81.60 \%$ and the very high (V) vulnerability zone for $7.93 \%$ in 2018. From 2000 to the present, the proportion of very low vulnerability zones in groundwater has been gradually increasing, but at the same time the very high vulnerability zones have also been increasing, with extreme cases. This is related to the 


\subsection{Discussion}

The concept of the DRASTIC model is used to evaluate groundwater vulnerability

450 in the area. The traditional DRASTIC was first used to evaluate the inherent

451 vulnerability of the aquifer, which is predominantly a low (II) vulnerability (41.25\%)

452 zone, with high (IV) and very high (V) vulnerability zones accounting for $20.47 \%$. As

453 can be seen from Fig. 3a, $50 \%$ of the points with nitrate $>50 \mathrm{mg} / \mathrm{L}$ fall into high (IV)

454 and very high (V) vulnerability zones, and the remaining $50 \%$ are mainly distributed in

455 low (II) vulnerability zones. Finally, $49.6 \%$ of nitrate $<50 \mathrm{mg} / \mathrm{L}$ points are distributed

456 in the very low (I) and low (II) vulnerability zones.

457 The seven parameters in the traditional DRASTIC model merely consider the

458 geological and hydrogeological conditions of the study area and do not consider the

459 effect of human activities on groundwater. The two added parameters, used to generate

460 the DRASTICLE model, combined with the three-scale AHP and WOE to modify the

461 weights of the parameters, found different results as follows. The results of the AHP-

462 DRASTIC model showed that the very low (I) vulnerability zones had the highest 463 distribution (55.05\%), and the high and very high vulnerability zones showed $19.82 \%$.

464 A total of $61.5 \%$ of the nitrate $>50 \mathrm{mg} / \mathrm{L}$ points fell in the high and very high 465 vulnerability zones and $19 \%$ in the very low vulnerability zone. Only $16.2 \%$ of the 466 nitrate $<50 \mathrm{mg} / \mathrm{L}$ points fell in the high and very high vulnerability zones and $64 \%$ in 467 the very low vulnerability zone. The evaluation results of AHP-DRASTICLE showed 
good dispersion, with $73.1 \%$ of nitrate $>50 \mathrm{mg} / \mathrm{L}$ points falling in high and very high

vulnerability zones and $82.5 \%$ of nitrate $<50 \mathrm{mg} / \mathrm{L}$ points falling in moderate, low, and very low vulnerability zones. After adding the two parameters, the accuracy of the evaluation results was further improved. While only $38.5 \%$ and $57.7 \%$ of the nitrate $>50$ $\mathrm{mg} / \mathrm{L}$ points for WOE-DRASTIC and WOE-DRASTICLE fell in the high and very high vulnerability zones, respectively, $94.7 \%$ and $77.6 \%$ of the nitrate $<50 \mathrm{mg} / \mathrm{L}$ points fell in the very low vulnerability zone. These results show that the evaluation results are more reliable with the addition of two parameters and improved parameter weighting. impact (1.668) on vulnerability, implying that shallower groundwater levels are not necessarily more vulnerable to pollution. Moreover, with increased net recharge to the aquifer, the chance of contaminants entering the groundwater becomes greater and the degree of protection against pollution becomes smaller, with net recharge at 177.8-254

$481 \mathrm{~mm}$ having the greatest impact. In general for aquifer media, the larger the medium 482 particles, the more fissures in the aquifer, and the higher the permeability; thus, the 483 greater the vulnerability of the aquifer. This was reflected in the model results, which 484 indicated that sand and gravel had the highest rates. Generally, the type of soil, amount 485 of expansion and shrinkage, and size of the media particles determine the size of soil 486 contamination susceptibility. Soils with relatively thick layers, high organic matter 487 content, and smaller particles have a high capacity to absorb contaminants, as well as 488 good anti-fouling properties, and low vulnerability. The results of this study show that 
soil media had great influence on loam, but not gravel. In general regarding topography,

490 the topographic slope affects the surface runoff volume, runoff velocity, runoff direction,

491 and residence time. The gentler the slope, the more pollutants leach, and the more likely

492 they will leach into the groundwater. The results of this study showed that topography

493 had the greatest effect at $2-6 \%$, not $0-2 \%$ as was expected from research by Khosravi

494 et al. (2018). In general, if the clay gravel content in the vadose zone is higher and the

495 granules are finer, the permeability of groundwater will be lower. In this study, the WOE

496 results show that the impact of the vadose zone had the greatest influence on sand and

497 gravel. Generally, the hydraulic conductivity coefficient of an aquifer reflects the

498 hydraulic permeability of an aquifer, which determines the migration rate of pollutants

499 in the aquifer and the difficulty of pollutants entering the groundwater system. In this

500 study, the results showed that when the conductivity of the aquifer was $>81.5 \mathrm{~m} / \mathrm{d}$, the

501 groundwater vulnerability was high. The artificial surface had the greatest influence on

502 the groundwater vulnerability assessment, likely because the farmers raise livestock

503 and grow crops and vegetables on their land, thus the associated animal waste,

504 pesticides, and fertilizers can lead to substantial pollution of groundwater. The degree

505 of groundwater extraction at $50-70 \%$ had the greatest effect on groundwater pollution 506 probability.

507 The AUC of the ROC curve shows that both the improved AHP-DRASTIC and

508 WOE-DRASTIC had better evaluation results than the traditional DRASTIC.

509 Meanwhile, AHP-DRASTICLE was better than AHP-DRASTIC, indicating that the 
510 evaluation results are more reliable with the addition of two evaluation factors for the

511 influence of human activities. The result of WOE-DRASTIC was better than that of

512 WOE-DRASTICLE because of no enough training points. Findings suggest that both

513 weight and evaluation factors should be further considered in the improvement of the

514 model.

\section{5. Conclusions}

516 This study evaluates the vulnerability of groundwater in Baicheng City and

517 optimizes the traditional DRASTIC method to better represent the actual vulnerability

518 distribution of groundwater. The factors and weights of the DRASTIC method were

519 improved. In consideration of the influence of human activities on groundwater, two

520 factors, land use and degree of groundwater extraction, were added to the evaluation

521 factors. The three-scale AHP and WOE methods were used to improve the weight of

522 the factors. The results of the five models (DRASTIC, AHP-DRASTIC, AHP-

523 DRASTICLE, WOE-DRASTIC, WOE-DRASTICLE) were compared using the ROC

524 curve. Results showed that the model improvements proposed in this study had obvious

525 effects: the model evaluation results were more accurate and had a higher correlation

526 with nitrate concentration. Moreover, the evaluation results were shown to have

527 improved accuracy after adding two factors to the AHP method. For the WOE method,

528 the AUC of WOE-DRASTICLE was smaller than that of WOE-DRASTIC, which is to

529 in the case of the few training points, the fewer evaluation factors, hence the evaluation

530 results had higher accuracy. In the future research, if more training points exist, it can 
531 be considered to add more evaluation factors into the WOE method.

532 The WOE-DRASTIC model was selected to evaluate the groundwater 533 vulnerability of Baicheng City in 2000 and 2010 and found that the groundwater 534 vulnerability in this region was mainly very low and low. From 2000 to 2018, the 535 proportion of low groundwater vulnerability also increased gradually from $72.63 \%$ to $53681.60 \%$. The high vulnerability was distributed in the Taoer River fan in the northwest 537 of the study area. Importantly, it should be noted that groundwater pollution may still 538 occur in very low or low vulnerability areas, though compared with areas of high 539 vulnerability, these areas are less vulnerable to human activities and natural 540 environmental pollution. Overall, it is recommended that government departments

541 should facilitate reasonable control of groundwater pollution prevention and extraction

542 according to changes in groundwater vulnerability in the region. This study therefore 543 provides a theoretical basis for the Baicheng municipal government to manage and 544 exploit groundwater resources.

\section{Supplementary Material}




\begin{tabular}{|c|c|c|c|c|c|c|c|c|c|c|c|}
\hline Factors & Range & Class & No.of pixels & $\begin{array}{c}\text { Percentage of } \\
\text { domain }(\%)\end{array}$ & $\begin{array}{l}\text { No.of } \\
\text { nitrate }\end{array}$ & $\begin{array}{c}\text { Percentage of } \\
\text { nitrate }(\%)\end{array}$ & $\mathrm{W}+$ & W- & $\mathrm{Sc}$ & $\mathrm{C}$ & $\mathrm{C} / \mathrm{Sc}$ \\
\hline \multirow[t]{5}{*}{$\mathrm{D}$} & $15.2-22.9$ & 3 & 19525 & 0.07 & 0 & 0.00 & None & 0.001 & None & None & None \\
\hline & $9.1-15.2$ & 5 & 1477578 & 5.16 & 1 & 3.85 & -0.294 & 0.014 & 1.020 & -0.308 & -0.302 \\
\hline & $4.6-9.1$ & 7 & 20997450 & 73.36 & 23 & 88.46 & 0.187 & -0.837 & 0.614 & 1.024 & 1.668 \\
\hline & $1.5-4.6$ & 9 & 6116909 & 21.37 & 2 & 7.69 & -1.022 & 0.160 & 0.736 & -1.182 & -1.606 \\
\hline & $0-1.5$ & 10 & 12045 & 0.04 & 0 & 0.00 & None & 0.000 & None & None & None \\
\hline \multirow[t]{3}{*}{$\mathrm{R}$} & $50.8-101.6$ & 3 & 31404 & 88.35 & 21 & 80.77 & -0.090 & 0.501 & 0.498 & -0.591 & -1.187 \\
\hline & $101.6-177.8$ & 6 & 278 & 0.78 & 0 & 0.00 & None & 0.008 & None & None & None \\
\hline & $177.8-254$ & 8 & 3862 & 10.87 & 5 & 19.23 & 0.571 & -0.099 & 0.498 & 0.669 & 1.345 \\
\hline \multirow[t]{3}{*}{ A } & Metamorphic/Igneous & 3 & 1706500 & 5.96 & 3 & 11.54 & 0.661 & -0.061 & 0.614 & 0.722 & 1.176 \\
\hline & Massive Sandstone & 6 & 25564772 & 89.28 & 17 & 65.38 & -0.311 & 1.172 & 0.412 & -1.483 & -3.598 \\
\hline & Sand and Gravel & 8 & 1364024 & 4.76 & 6 & 23.08 & 1.578 & -0.214 & 0.465 & 1.791 & 3.849 \\
\hline \multirow[t]{3}{*}{$\mathrm{S}$} & Loam & 5 & 2099007 & 7.34 & 6 & 23.08 & 1.146 & -0.186 & 0.465 & 1.332 & 2.861 \\
\hline & Sand & 9 & 23941055 & 83.71 & 20 & 76.92 & -0.085 & 0.348 & 0.465 & -0.433 & -0.930 \\
\hline & Gravel & 10 & 2559880 & 8.95 & 0 & 0.00 & None & 0.094 & None & None & None \\
\hline \multirow[t]{5}{*}{$\mathrm{T}$} & $>18$ & 1 & 2090 & 0.01 & 0 & 0.00 & None & 0.000 & None & None & None \\
\hline & $12-18$ & 3 & 10724 & 0.04 & 0 & 0.00 & None & 0.000 & None & None & None \\
\hline & $6-12$ & 5 & 94208 & 0.33 & 0 & 0.00 & None & 0.003 & None & None & None \\
\hline & $2-6$ & 9 & 1046784 & 3.66 & 1 & 3.85 & 0.050 & -0.002 & 1.020 & 0.052 & 0.051 \\
\hline & $0-2$ & 10 & 27451069 & 95.97 & 25 & 96.15 & 0.002 & -0.048 & 1.020 & 0.050 & 0.049 \\
\hline \multirow[t]{4}{*}{ I } & Silt/Clay & 1 & 2738401 & 9.61 & 5 & 19.23 & 0.694 & -0.113 & 0.498 & 0.806 & 1.620 \\
\hline & limit loam & 5 & 7216826 & 25.33 & 3 & 11.54 & -0.786 & 0.169 & 0.614 & -0.956 & -1.557 \\
\hline & Sandstone & 6 & 17277701 & 60.63 & 13 & 50.00 & -0.193 & 0.239 & 0.392 & -0.432 & -1.101 \\
\hline & Sand and Gravel & 8 & 1263549 & 4.43 & 5 & 19.23 & 1.467 & -0.168 & 0.498 & 1.635 & 3.287 \\
\hline
\end{tabular}




\begin{tabular}{|c|c|c|c|c|c|c|c|c|c|c|c|}
\hline \multirow[t]{6}{*}{$\mathrm{C}$} & $0-4.1$ & 1 & 7210489 & 25.19 & 2 & 7.69 & -1.186 & 0.210 & 0.736 & -1.396 & -1.897 \\
\hline & $4.1-12.2$ & 2 & 8382437 & 29.29 & 3 & 11.54 & -0.931 & 0.224 & 0.614 & -1.155 & -1.882 \\
\hline & $12.2-28.5$ & 4 & 3721649 & 13.00 & 1 & 3.85 & -1.218 & 0.100 & 1.020 & -1.318 & -1.292 \\
\hline & $28.5-40.7$ & 6 & 1931868 & 6.75 & 1 & 3.85 & -0.562 & 0.031 & 1.020 & -0.593 & -0.581 \\
\hline & $40.7-81.5$ & 8 & 2781926 & 9.72 & 3 & 11.54 & 0.172 & -0.020 & 0.614 & 0.192 & 0.313 \\
\hline & $>81.5$ & 10 & 4595235 & 16.05 & 16 & 61.54 & 1.344 & -0.781 & 0.403 & 2.124 & 5.270 \\
\hline \multirow[t]{7}{*}{$\mathrm{L}$} & Forest & 1 & 88719 & 0.31 & 0 & 0.00 & None & 0.003 & None & None & None \\
\hline & natural grass & 2 & 5762547 & 20.13 & 3 & 11.54 & -0.556 & 0.102 & 0.614 & -0.659 & -1.073 \\
\hline & Wetland & 3 & 321146 & 1.12 & 0 & 0.00 & None & 0.011 & None & None & None \\
\hline & Water Bodies & 5 & 848979 & 2.97 & 0 & 0.00 & None & 0.030 & None & None & None \\
\hline & Cultivated Land & 6 & 17314166 & 60.48 & 6 & 23.08 & -0.963 & 0.666 & 0.465 & -1.629 & -3.501 \\
\hline & Bareland & 7 & 3401822 & 11.88 & 0 & 0.00 & None & 0.127 & None & None & None \\
\hline & Artificial Surface & 10 & 891087 & 3.11 & 17 & 65.38 & 3.045 & -1.029 & 0.412 & 4.074 & 9.883 \\
\hline \multirow[t]{4}{*}{ E } & $0-20 \%$ & 1 & 1127 & 3.17 & 0 & 0.00 & None & 0.032 & None & None & None \\
\hline & $20 \%-50 \%$ & 3 & 25153 & 70.77 & 11 & 42.31 & -0.514 & 0.680 & 0.397 & -1.194 & -3.007 \\
\hline & $50 \%-70 \%$ & 6 & 6198 & 17.44 & 10 & 38.46 & 0.791 & -0.294 & 0.403 & 1.085 & 2.690 \\
\hline & $80 \%-100 \%$ & 9 & 3066 & 8.63 & 5 & 19.23 & 0.802 & -0.123 & 0.498 & 0.925 & 1.858 \\
\hline
\end{tabular}


549

\section{Acknowledgment}

This study was supported by the National Natural Science Foundation of China, Research on the Impact of In-situ Oil Shale Exploitation on Groundwater Environment [project number 41572216], the China Geological Survey project, regional water resources survey methods, and groundwater ecological threshold survey research [project number DD20190340], Geological Exploration Fund of Jilin Province, Geothermal Resources Survey in the Middle and West of Jilin Province [project number 2018-13]; Special Project of the Provincial University Co-Construction ProgramFrontier Science and Technology Guidance Category, Research on the Interdependent Ecosystem and Sustainable Utilization of Natural Mineral Water in Changbai Mountain [project number SXGJQY2017-6]; Key research and development program of Shaanxi Province, Construction of Big Data Platform for Geotechnical Engineering [project number 2017ZDCXL-SF-03-01-01]. The authors would like to thank Jilin Jingyu field scientific observation and research base of volcanoes and mineral springs, which provided the necessary data to conduct this study. We thank the anonymous reviewers and editors who contributed valuable comments, which were useful in improving the quality of the manuscript.

Author contribution: Mingjun Liu: Writing - original draft, Data curation, Formal analysis. Changlai Xiao: Conceptualization, Writing -review, Supervision, Funding acquisition. Xiujuan Liang: Methodology \& editing, Formal analysis.

Data availability The dataset used and/or analyzed during the current study are 
570 available from the corresponding author on reasonable request.

571 Compliance with ethical standards

572 Ethics approval and consent to participate Not applicable.

573 Consent for publication Not applicable.

574 Declaration of competing interest

575 The authors declare that they have no known competing financial interests or 576 personal relationships that could have appeared to influence the work reported in this 577 paper.

578

579

580 References

581 Abu-Bakr, H. A. e.-A. (2020). Groundwater vulnerability assessment in different types 582 of aquifers. Agricultural Water Management, 240. doi:10.1016/j.agwat.2020.106275

584 Agterberg, \& F., P. (1989). Computer programs for mineral exploration. Science, 585 245(4913), 76-81. doi:10.1126/science.245.4913.76

586 Al-Adamat, R. A. N., Foster, I. D. L., \& Baban, S. M. J. (2003). Groundwater 587 vulnerability and risk mapping for the Basaltic aquifer of the Azraq basin of Jordan 588 using GIS, Remote sensing and DRASTIC. Applied Geography, 23(4), 303-324. 589 doi:10.1016/j.apgeog.2003.08.007

590 Aller, L., Bennett, T., Lehr, J., Petty, R., \& Hackett, G. (1987). DRASTIC: Standardized 

system for evaluating groundwater pollution potencial using hydrogeologic settings. Journal of the Geological Society of India, 29.

593 Almasri, M. N. (2008). Assessment of intrinsic vulnerability to contamination for Gaza 594 coastal aquifer, Palestine. J Environ Manage, 88(4), 577-593. doi:10.1016/j.jenvman.2007.01.022

An, Y., \& Lu, W. (2018). Assessment of groundwater quality and groundwater vulnerability in the northern Ordos Cretaceous Basin, China. Arabian Journal of Geosciences, 11(6). doi:10.1007/s12517-018-3449-y

Antonakos, A. K., \& Lambrakis, N. J. (2007). Development and testing of three hybrid 600 288-304. doi:10.1016/j.jhydrol.2006.08.014 GIS-based groundwater potential mapping in Shahroud plain, Iran. A comparison among statistical (bivariate and multivariate), data mining and MCDM approaches. Science Of the Total Environment, 658, 160-177. DRASTIC model for assessing aquifer vulnerability in Kakamigahara Heights, Gifu Prefecture, central Japan. Sci Total Environ, 345(1-3), 127-140. doi:10.1016/j.scitotenv.2004.11.005 
612 Bai, L., Wang, Y., \& Meng, F. (2012). Application of DRASTIC and extension theory

613 in the groundwater vulnerability evaluation. Water and Environment Journal, 26(3),

614 381-391. doi:10.1111/j.1747-6593.2011.00298.x

615 Barber, Bates, C., Barron, L., \& Allison, R. (1998). Comparison of standardised and

616 region-specific methods for assessment of the vulnerability of groundwater to

617 pollution; a case study in an agricultural catchment.

618 Barzegar, R., Moghaddam, A. A., \& Baghban, H. (2015). A supervised committee

619 machine artificial intelligent for improving DRASTIC method to assess

620 groundwater contamination risk: a case study from Tabriz plain aquifer, Iran.

621 Stochastic Environmental Research and Risk Assessment, 30(3), 883-899.

622 doi:10.1007/s00477-015-1088-3

623 Barzegar, R., Moghaddam, A. A., Deo, R., Fijani, E., \& Tziritis, E. (2018). Mapping

624 groundwater contamination risk of multiple aquifers using multi-model ensemble

625 of machine learning algorithms. Sci Total Environ, 621, 697-712.

626 doi:10.1016/j.scitotenv.2017.11.185

627 Bojórquez-Tapia, L. A., Cruz-Bello, G. M., Luna-González, L., Juárez, L., \& Ortiz-

628 Pérez, M. A. (2009). V-DRASTIC: Using visualization to engage policymakers in 629 groundwater vulnerability assessment. Journal of Hydrology, 373(1-2), 242-255.

$630 \quad$ doi:10.1016/j.jhydrol.2009.05.005

631 Bonfanti, M., Ducci, D., Masetti, M., Sellerino, M., \& Stevenazzi, S. (2016). Using 632 statistical analyses for improving rating methods for groundwater vulnerability in 
635 Brindha, K., \& Elango, L. (2015). Cross comparison of five popular groundwater 636 pollution vulnerability index approaches. Journal of Hydrology, 524, 597-613. doi:10.1016/j.jhydrol.2015.03.003

638 Feng, X. (2019). Study on the Protection Scheme of Groundwater Resources in 639 Baicheng City (master), Jilin University, Available from Cnki

640 Ferreira, J. P. L., \& Oliveira, M. M. (2004). Groundwater vulnerability assessment in 641 Portugal. Geofísica Internacional, 43(4), 541-550.

642 Ghazavi, R., \& Ebrahimi, Z. (2015). Assessing groundwater vulnerability to 643 contamination in an arid environment using DRASTIC and GOD models. 644 International Journal of Environmental Science and Technology, 12(9), 2909-2918. doi:10.1007/s13762-015-0813-2

646 Gogu, R. C., \& Dassargues, A. (2000). Current trends and future challenges in 647 groundwater vulnerability assessment using overlay and index methods. 648 Environmental Geology, 39(6), 549-559. doi:DOI 10.1007/s002540050466

649 Huan, H., Wang, J., \& Teng, Y. (2012). Assessment and validation of groundwater 650 vulnerability to nitrate based on a modified DRASTIC model: a case study in Jilin 651 City of northeast China. Sci Total Environ, 440, 14-23. 652 doi:10.1016/j.scitotenv.2012.08.037

653 Huan, H., Wang, J. S., Zhai, Y. Z., Xi, B. D., Li, J., \& Li, M. X. (2016). Quantitative 

based on process-based simulation model. Science Of the Total Environment, 550, 768-784. doi:10.1016/j.scitotenv.2016.01.144 573. doi:10.1007/s12594-019-1218-5

661 Kazakis, N., \& Voudouris, K. S. (2015). Groundwater vulnerability and pollution risk 662 quantitative parameters. Journal of Hydrology, 525, 13-25. doi:10.1016/j.jhydrol.2015.03.035

Khan, R., \& Jhariya, D. C. (2019). Assessment of Groundwater Pollution Vulnerability $\mathrm{X}$

669 Khosravi, K., Sartaj, M., Tsai, F. T., Singh, V. P., Kazakis, N., Melesse, A. M., Prakash, 670 I., Tien Bui, D., \& Pham, B. T. (2018). A comparison study of DRASTIC methods 671 with various objective methods for groundwater vulnerability assessment. Sci Total Environ, 642, 1032-1049. doi:10.1016/j.scitotenv.2018.06.130

673 Mukherjee, I., \& Singh, U. K. (2020). Delineation of groundwater potential zones in a 674 drought-prone semi-arid region of east India using GIS and analytical hierarchical 
676 O'Brien, R. M. (2007). A caution regarding rules of thumb for variance inflation factors. Quality \& Quantity, 41(5), 673-690. doi:10.1007/s11135-006-9018-6

Omotola, O. O., Oladapo, M. I., \& Akintorinwa, O. J. (2020). Modeling assessment of groundwater vulnerability to contamination risk in a typical basement terrain case of vulnerability techniques application comparison study. Modeling Earth Systems and Environment, 6(3), 1253-1280. doi:10.1007/s40808-020-00720-1 weighting in DRASTIC modeling. Sci Total Environ, 505, 474-486. doi:10.1016/j.scitotenv.2014.09.092

Perrin, J., Cartannaz, C., Noury, G., \& Vanoudheusden, E. (2015). A multicriteria 686

Rezaei, F., Safavi, H. R., \& Ahmadi, A. (2013). Groundwater Vulnerability Assessment approach to karst subsidence hazard mapping supported by weights-of-evidence analysis. Engineering Geology, 197, 296-305. doi:10.1016/j.enggeo.2015.09.001

Saaty, T., \& Kearns, K. (1985). The Analytic Hierarchy Process. analytical planning, 692 19-62. doi:10.1016/B978-0-08-032599-6.50008-8 objective and subjective weighting methods for aquifer vulnerability assessment in 695 urban context. Journal of Hydrology, 541 , 1303-1315. 
697 Sener, E., \& Davraz, A. (2012). Assessment of groundwater vulnerability based on a 698 modified DRASTIC model, GIS and an analytic hierarchy process (AHP) method: 699 the case of Egirdir Lake basin (Isparta, Turkey). Hydrogeology Journal, 21(3), 701700 714. doi:10.1007/s10040-012-0947-y

701 Shrestha, S., Semkuyu, D. J., \& Pandey, V. P. (2016). Assessment of groundwater 702 vulnerability and risk to pollution in Kathmandu Valley, Nepal. Sci Total Environ, 703 556, 23-35. doi:10.1016/j.scitotenv.2016.03.021

704 Thirumalaivasan, D., Karmegam, M., \& Venugopal, K. (2003). AHP-DRASTIC: 705 software for specific aquifer vulnerability assessment using DRASTIC model and 706 8152(03)00051-3

708 Victorine Neh, A., Ako Ako, A., Richard Ayuk, A., \& Hosono, T. (2015). DRASTIC709 GIS model for assessing vulnerability to pollution of the phreatic aquiferous 710 formations in Douala-Cameroon. Journal of African Earth Sciences, 102, 180-190. doi:10.1016/j.jafrearsci.2014.11.001

712 Voutchkova, D. D., Schullehner, J., Rasmussen, P., \& Hansen, B. (2021). A high713 resolution nitrate vulnerability assessment of sandy aquifers (DRASTIC-N). $J$ 714 Environ Manage, 277, 111330. doi:10.1016/j.jenvman.2020.111330

715 Wang, J. L., \& Yang, Y. S. (2008). An approach to catchment-scale groundwater nitrate 716 risk assessment from diffuse agricultural sources: a case study in the Upper Bann, 
717 Northern Ireland. Hydrological Processes, 22(21), 4274-4286. 718 doi:10.1002/hyp.7036

719 Wu, X., Li, B., \& Ma, C. (2018). Assessment of groundwater vulnerability by applying 720 the modified DRASTIC model in Beihai City, China. Environ Sci Pollut Res Int, 721 25(13), 12713-12727. doi:10.1007/s11356-018-1449-9

722 Zhang, Z. J., Zuo, R. G., \& Xiong, Y. H. (2016). A comparative study of fuzzy weights 723 of evidence and random forests for mapping mineral prospectivity for skarn-type 724 Fe deposits in the southwestern Fujian metallogenic belt, China. Science China725 Earth Sciences, 59(3), 556-572. doi:10.1007/s11430-015-5178-3

726 Zuo, J. (1988). The indirect method of judgment matrix in analytic hierarchy process. 727 Systems engineering(06), 56-63. doi:CNKI:SUN:GCXT.0.1988-06-013 